\title{
Erratum zu: Hämatomneigung bei Lipödem: Kutane Genese oder Gerinnungsdefekt?
}

Online publiziert: 16. Februar 2021

(C) Springer-Verlag GmbH Austria, ein Teil von Springer Nature 2021

\section{Erratum zu:}

Wien Med Wochenschr 2020

https://doi.org/10.1007/s10354-020-00792-9

In der Originalpublikation des Beitrags kam es leider zu einem Fehler.

In der Affiliation von Dr. Sucker wurde eine falsche Angabe zur Stadt publiziert.

Die korrekte Affiliation lautet:

PD Dr. med. C. Sucker

Medizinisches Versorgungszentrum (MVZ) COAGUMED, Berlin, Deutschland

Medizinische Hochschule Brandenburg, Brandenburg an der Havel, Deutschland

Wir bitten, die Korrektur zu beachten und den Fehler zu entschuldigen.

Die Redaktion 